\title{
The evaluation of the relationship between childhood traumas and smoking addiction
}

\author{
Corresponding author: \\ Cenk Aypak, Department of Family \\ Medicine, University of Health Sciences, \\ Dışkapı Yıldırım Beyazıt Training and \\ Research Hospital, Ziraat District, \\ Sehit Ömer Halisdemir Str. No: 20 \\ Dıskapı- Altındag, Ankara 06100 Turkey; \\ e-mail: cenkaypak@yahoo.com
}

Medical Research Journal 2022; Volume 7, Number 1, 32-37 DOI: 10.5603/MRJ.a2022.0006 Copyright (C) 2022 Via Medica ISSN 2451-2591 e-ISSN 2451-4101

\begin{abstract}
Introduction. Data about the relationship between childhood traumas and cigarette smoking are scarce. In this study, the relationship between childhood abuse and smoking addiction was evaluated in adults. Material and methods. This research was carried out with the participation of 216 individuals (82 [38\%] women and 134 [62\%] men) over the age of 18 who applied to the Family Medicine Out-patient Clinics of a tertiary hospital. They were asked to answer the socio-demographic questions as well as the questionnaire forms containing the Fagerström Nicotine Addiction Test (FNAT) and Childhood Trauma Questionnaire (CTQ).

Results. The median age at which men start smoking was significantly lower than that of women (17 vs. 19 years; $p=0.007$ ). Men have higher rates of physical neglect than women $(p=0.001)$. No significant difference was found between the exposure of individuals to emotional, physical, sexual neglect and abuse and nicotine addiction levels after adjustment for age, gender and education level. However, a significant negative correlation was found between the FNAT score and the CTQ total score, emotional abuse score, physical neglect score, and emotional neglect score.

Conclusion. Contrary to the results in the literature, we did not find a directly proportional relationship between adverse childhood experiences and smoking addiction. This finding suggests that further studies should be done on whether adverse childhood experiences may lead not only to cigarette addiction but also to other serious conditions such as substance abuse, mental and physical health problems. Determinants of child maltreatment are multi-systemic, it therefore, makes sense that in counties with different social, cultural, and economic conditions, the consequences of child maltreatment will also be different. Key words: tobacco use disorder, child abuse, cigarette smoking
\end{abstract}

Med Res J 2022; 7 (1): 32-37

\section{Introduction}

The tobacco epidemic has been identified by the World Health Organization as one of the largest public health problems ever encountered in the world. It is known that this epidemic causes the death of approximately 8 million people every year. It is known that over 7 million of these deaths are caused by direct use of tobacco [1].

It is thought that $45 \%$ of people over the age of 15 are seriously addicted to cigarettes worldwide which indicates that the problem is particularly important for youth [1]. It is known that one of the two young people who try to smoke continues to smoke and those who start smoking before 20 years of age in our country constitute a significant part of those who smoke. Research has shown that the average age of smokers in Turkey shows that gradually decreases. As a result, the most vulnerable risk group of the cigarette epidemic are children and adolescents [2]. Besides many factors, it is known that emotional, physical, and sexual traumas in childhood cause an increase in smoking behavior in individuals who are at the stage of starting an active life struggle [3].

Child abuse is universally understood to include four main types: sexual abuse, physical abuse, emotional or psychological abuse, and neglect. Child abuse is a form of adverse childhood experiences (ACEs), a broad term that also includes exposure to family mental health problems, incarceration, substance 
use, parental separation/divorce, as well as poverty, bullying, racial discrimination, and separation from immigrant parents. Defining the nature of each form of child maltreatment is complex, but robust conceptual models have developed over time to establish growing consensus. Physical abuse is generally understood to involve intentional acts of physical force by a parent or caregiver; it is normally seen as excluding lawful corporal punishment. Sexual abuse involves contact and non-contact sexual acts, inflicted by an adult or child in a position of power over the victim, to seek or obtain physical or mental sexual gratification, when the child does not have capacity to provide consent, or has capacity but does not provide consent. Emotional or psychological abuse is inflicted by a parent or caregiver and includes hostile interactions (such as belittling, degrading, shaming, denigrating or ridiculing a child, and rejection of the child), emotional unavailability (ignoring a child), developmentally inappropriate interactions, failure to acknowledge the child's individuality, and failure to integrate the child into the social world. Neglect involves parental or caregiver omissions to provide the necessities of life, as suited to the child's developmental stage, and as recognised by the child's cultural context. Neglect includes multiple dimensions, including physical, emotional, medical, environmental, supervisory, and educational neglect [4-6].

The aim of our study is to evaluate whether a relationship exists between cigarette smoking addiction and childhood traumas.

\section{Material and methods}

This research was carried out with the participation of 216 patients over the age of 18 who applied to the Family Medicine Out-patient Clinics of a tertiary hospital. The participants of the study were informed about the research and after receiving their approval, they were asked to answer the socio-demographic questions as well as the questionnaire forms containing the Fagerström Nicotine Addiction Test (FNAT) and Childhood Trauma Questionnaire (CTQ).

\section{Fagerström Nicotine Addiction Test (FNAT)}

In FNAT, which is widely used to determine the severity of addiction, participants are subjected to a scoring system based on their answers to six questions. A higher level of addiction was associated with having a higher score. The scores range from 0 to 10 , and the participants are divided into 5 groups according to their dependence levels: very low, low, medium, high, and very high. Scores between 0-2 are considered to be very low, those between 3-4 as low, those between
5 as a medium, those between 6-7 as high level, and those between 8-10 as very highly dependent [7].

\section{Childhood Trauma Scale (Questionnaire) (CTQ)}

Childhood Trauma Questionnaire (CTQ) consists of 28 questions and evaluates the childhood ages of individuals between "never" and "very often". Eighteen of the questions are negative and ten are positive. The evaluation of positive and negative questions is different. Childhood Trauma Questionnaire, the former version of which consisted of 53 questions, was shortened by its original author, and now it has 28 questions [8]. With this scale, scores on childhood sexual, physical, emotional abuse, and emotional and physical neglect are obtained.

\section{Statistics}

A statistical assessment of the data was made using PASW Statistics (Version 18.0. Chicago: SPSS Inc.). Descriptive statistics were used to evaluate patient characteristics and the frequency of parameters. The compliance of the variables obtained in this study to the normal distribution, the Shapiro-Wilk test was used. The differences between the groups, Chi-Square, Mann Whitney U, and Kruskal Wallis tests were used. Correlation between measurement parameters was analyzed with Spearman Correlation Test. In all tests, $p$ values of $<0.05$ were considered statistically significant.

\section{Results}

The study participants included a total of 82 (38\%) women and 134 (62\%) men. The socio-demographic data of the individuals in our study according to their smoking status are presented in Table 1.

There is a significant difference between individuals' age of starting smoking and nicotine addiction levels $(p=0.011)$. The level of nicotine addiction was found to be higher in those who started smoking later in life. The relationship between the ages of starting smoking and nicotine addiction levels was in Table 2.

The median age at which men start smoking was 17 years (min: 9; max: 28) and it is significantly lower than that of women (median $=19$ years, $\min$ : 10; max: 35) $(p=0.007)$.

When the individuals were analyzed according to their gender, it was found that $34.1 \%$ of women and $56.7 \%$ of men were exposed to physical neglect. Men have significantly higher rates of physical neglect than women ( $p=0.001$ ) (Tab. 3). Since the information presented in this table covers all smokers and non-smokers, it can be emphasized that the male gender has 
Table 1. Distribution of smokers and non-smokers by demographic characteristics

\begin{tabular}{|c|c|c|c|c|c|c|}
\hline & & \multicolumn{4}{|c|}{ Do you smoke? } & \multirow[t]{3}{*}{$\mathbf{p}$} \\
\hline & & \multicolumn{2}{|c|}{ No $(n=116)$} & \multicolumn{2}{|c|}{ Yes $(n=100)$} & \\
\hline & & $\mathbf{n}$ & $\%$ & $\mathbf{n}$ & $\%$ & \\
\hline \multirow[t]{2}{*}{ Sex } & Female & 54 & $54 / 116(0.5)$ & 28 & $28 / 100(0.3)$ & 0.007 \\
\hline & Male & 62 & $62 / 116(0.5)$ & 72 & $72 / 100(0.7)$ & \\
\hline \multirow[t]{4}{*}{ Education Status } & Primary school and below & 15 & $15 / 116(0.1)$ & 16 & $16 / 100(0.2)$ & 0.042 \\
\hline & Middle School & 24 & $24 / 116(0.2)$ & 10 & $10 / 100(0.1)$ & \\
\hline & High School & 31 & $31 / 116(0.3)$ & 41 & $41 / 100(0.4)$ & \\
\hline & University and above & 46 & $46 / 116(0.4)$ & 33 & $33 / 100(0.3)$ & \\
\hline \multirow[t]{4}{*}{ Age Groups } & $18-30$ & 44 & $44 / 116(0.4)$ & 36 & $36 / 100(0.4)$ & 0.603 \\
\hline & $31-40$ & 33 & $33 / 116(0.3)$ & 34 & $34 / 100(0.3)$ & \\
\hline & $41-50$ & 24 & $24 / 116(0.2)$ & 22 & $22 / 100(0.2)$ & \\
\hline & $51+$ & 15 & $15 / 116(0.1)$ & 8 & $8 / 100(0.1)$ & \\
\hline
\end{tabular}

Table 2. Comparation of nicotine addiction levels according to the Fagerström Nicotine Addiction test with ages of starting smoking

\begin{tabular}{lcccc}
\hline Nicotine addiction levels & $\mathbf{n}$ & \multicolumn{2}{c}{ The ages of starting smoking } & p* \\
\cline { 2 - 3 } & & Mean & \pm SD & 0.01 \\
0-2 (Very low addiction) & 11 & 15.6 & 3.6 & \\
3-4 (Low addiction) & 26 & 16.1 & 3.1 & \\
5 (Average score) & 9 & 15.6 & 3.3 \\
6-7 (High addiction) & 20 & 18.8 & 4.2 & \\
8-10 (Very high addiction) & 34 & 18.7 & 4.1 & \\
\hline
\end{tabular}

* - Kruskall-Wallis test; SD — Standard deviation

Table 3. Trauma exposure according to gender

\begin{tabular}{|c|c|c|c|c|c|c|}
\hline & & \multicolumn{2}{|c|}{ Female } & \multicolumn{2}{|c|}{ Male } & \multirow[t]{2}{*}{$\mathbf{p}$} \\
\hline & & $\mathbf{n}$ & $\%$ & $\mathbf{n}$ & $\%$ & \\
\hline \multirow[t]{2}{*}{ Emotional abuse } & No & 64 & (78) & 107 & (79.9) & 0.752 \\
\hline & Yes & 18 & (22) & 27 & $(20.1)$ & \\
\hline \multirow[t]{2}{*}{ Emotional neglect } & No & 47 & $(57.3)$ & 63 & $(47.0)$ & 0.142 \\
\hline & Yes & 35 & $(42.7)$ & 71 & $(53.0)$ & \\
\hline \multirow[t]{2}{*}{ Physicial abuse } & No & 76 & $(92.7)$ & 114 & $(85.1)$ & 0.095 \\
\hline & Yes & 6 & $(7.3)$ & 20 & $(14.9)$ & \\
\hline \multirow[t]{2}{*}{ Physicial neglect } & No & 54 & $(65.9)$ & 58 & $(43.3)$ & 0.001 \\
\hline & Yes & 28 & $(34.1)$ & 76 & $(56.7)$ & \\
\hline \multirow[t]{2}{*}{ Sexual abuse } & No & 69 & $(84.1)$ & 107 & $(79.9)$ & 0.430 \\
\hline & Yes & 13 & $(15.9)$ & 27 & $(20.1)$ & \\
\hline
\end{tabular}

a disadvantage in terms of experiencing physical neglect in childhood.

No statistically significant difference was found between the exposure of individuals to emotional, physical, sexual neglect and abuse and nicotine addiction levels (Tab. 4). When the correlation between Fagerström addiction score and CTQ total and sub-scores was examined, a significant nega- 
Table 4. Trauma exposure according to the smoking status of individuals

\begin{tabular}{|c|c|c|c|c|c|c|}
\hline & & \multicolumn{4}{|c|}{ Do you smoke? } & \multirow{3}{*}{$\mathbf{p}$} \\
\hline & & \multicolumn{2}{|c|}{ No $(n=116)$} & \multicolumn{2}{|c|}{ Yes $(n=100)$} & \\
\hline & & $\mathbf{n}$ & $\%$ & $\mathbf{n}$ & $\%$ & \\
\hline \multirow[t]{2}{*}{ Emotional abuse } & No & 91 & $(78.4)$ & 80 & $(80.0)$ & 0.779 \\
\hline & Yes & 25 & $(21.6)$ & 20 & $(20.0)$ & \\
\hline \multirow[t]{2}{*}{ Emotional neglect } & No & 59 & $(50.9)$ & 51 & $(51.0)$ & 0.984 \\
\hline & Yes & 57 & $(49.1)$ & 49 & $(49.0)$ & \\
\hline \multirow[t]{2}{*}{ Physicial abuse } & No & 101 & $(87.1)$ & 89 & $(89.0)$ & 0.664 \\
\hline & Yes & 15 & $(12.9)$ & 11 & $(11.0)$ & \\
\hline \multirow[t]{2}{*}{ Physicial neglect } & No & 62 & $(53.4)$ & 50 & $(50.0)$ & 0.613 \\
\hline & Yes & 54 & $(46.6)$ & 50 & $(50.0)$ & \\
\hline \multirow[t]{2}{*}{ Sexual abuse } & No & 98 & $(84.5)$ & 78 & $(78.0)$ & 0.221 \\
\hline & Yes & 18 & $(15.5)$ & 22 & $(22.0)$ & \\
\hline
\end{tabular}

Table 5. Correlation analysis between the Fagerström Nicotine Addiction test score and Childhood Trauma Questionnaire (CTQ) scores

\begin{tabular}{lcc}
\hline & rho & p \\
\hline CTQ & -0.333 & 0.001 \\
Emotional neglect & -0.226 & 0.024 \\
Emotional abuse & -0.257 & 0.010 \\
Physical neglect & -0.307 & 0.002 \\
Physical abuse & -0.193 & 0.054 \\
Sexual abuse & -0.047 & 0.641 \\
\hline
\end{tabular}

tive correlation was found between the Fagerström addiction score and the CTQ total score, emotional abuse score, physical neglect score, and emotional neglect score (Tab. 5).

\section{Discussion}

Tobacco use is the most common preventable cause of death. Various studies have been conducted on the relationship between smoking addiction and childhood traumas and various psychosocial factors [4-11]. In this study, the level of cigarette addiction and the relationship between this addiction and childhood trauma were investigated.

A total of $34.1 \%$ of women and $53.7 \%$ of men who participated in our study were found to be smokers. Those ratios are higher than the general population rates in our country. According to The Global Adult To- bacco Survey (GATS), Turkey has stated that cigarette addiction rate was $31.2 \%$ in 2008 , while the result of anti-smoking policies falls to $27.1 \%$ in 2012 [9]. When the age groups were evaluated among themselves, we found that the highest prevalence of smoking was in the 31-40 age group. Consistent with our findings, the 25-44 age group had the highest prevalence of smoking in both genders in GATS.

A significant relationship was found between the age of onset and nicotine addiction level in cigarette addiction. Accordingly, the age of starting smoking (mean: $18.7 \pm 4$ ) of those with high addiction scores (6-10) was found to be significantly higher than the age of those (mean: $15.5 \pm 3$ ) with low addiction scores $(0-5)$. This means that those who started smoking at an older age had a higher level of addiction to smoking. A significant portion of cigarette addiction is known to produce among individuals who started using cigarettes, before the age of 20 , our results are consistent with a previous study [9]. In a study by Martinez-Ortega et al. [12], addiction scores were found to be significantly higher in those who started smoking at an early age, whereas in our study, a positive correlation was found between age at onset and addiction scores. In other words, the addiction scores of those who started at an older age were higher. In another study conducted by Oncel et al. [13] in our country, a negative correlation was found between age of onset and addiction scores, unlike our study.

Our results also revealed that the effect of physical neglect on cigarette smoking was significant for men. It has been found in previous research that a relationship between physical childhood neglect with cigarette smoking was only present among males [14]. 
In a study conducted by Roberts et al. [15] among young adults, the prevalence of smoking was found to be significantly higher in those who experienced trauma in childhood. They reported that $48.3 \%$ of those who had sexual trauma in childhood were smoking, while this rate was $41 \%$ for those who were not exposed. Accordingly, exposure to sexual trauma in childhood increases the risk of smoking addiction by 1.43 (95\% Cl: 1.07-1.9). In addition, in the same study, while $45.4 \%$ of those who had physical trauma in childhood were smoking, this rate was found to be $39.3 \%$ in those who were not exposed. Exposure to physical trauma in childhood increases the risk of smoking addiction by $1.28(95 \%$ Cl: 1.13-1.45) times. In our study, when the variables of gender, educational status and age were adjusted, no significant relationship was found with cigarette addiction in any of the subgroups of emotional abuse, physical abuse, sexual abuse, emotional neglect, and physical neglect. On the other hand, in our study, a significant and negative correlation was found between the CTQ score and sub-scores (emotional abuse, physical neglect, emotional neglect) and the nicotine addiction score. Those findings and possible underlying factors should be evaluated further.

In the study of Nichols et al. [16], it was found that exposure to physical and sexual trauma in childhood increased the risk of smoking addiction approximately 3.5 times in women. They stated, unlike previous studies, sexual trauma was to be a greater risk factor for smoking addiction than physical trauma in women. In another study, it was revealed that while the violence experienced in both male and female university students during childhood did not affect alcohol addiction, it was a risk factor for cigarette addiction [17]. In this study, the smoking prevalence of female students who were exposed to violence was $11.7 \%$, while this rate was $2.8 \%$ for those who did not. While the smoking prevalence of male students who were exposed to violence was $16.3 \%$, this rate was $5 \%$ for those who were not exposed to violence.

In the literature, other studies show that adverse events experienced in childhood are associated with increased risk of smoking and being addicted to smoking. For instance, in a cohort study in Australia where Mamun et al. [18] investigated the relationship between childhood sexual trauma and nicotine addiction, 2571 singleton babies born between 1981 and 1984 were followed for 21 years. In this study in which DSM-IV criteria were used in terms of nicotine addiction, it was found that $16.6 \%$ of the participants met the addiction criteria. It was stated that $23.5 \%$ of the participants were exposed to sexual trauma at least once before the age of 16. At the end of this study, regardless of the form of childhood sexual trauma (penetrating or non-penetrating), it was determined that the nicotine addiction of the youth was significantly higher than those who were not exposed to sexual trauma. While the risk of nicotine addiction is 2.2 (\%95 Cl: 1.69-2.87) times higher in exposure to non-penetrating sexual trauma, this rate is 3.56 (\%95 Cl: $2.59-4.9)$ times higher in penetrating sexual trauma.

\section{Limitations}

The self-report emerges as the most important limitation in this study. Incomplete misrepresentation in the declaration of negative experiences in childhood, especially due to moral and cultural reasons in our country, can directly affect the result of the study. Secondly, the fact that the study is conducted on a limited population and sample may cause it not to be generalized to society. In addition, the fact that CTQ scale which evaluates childhood traumas may not be used sufficiently in our country. For instance, Grassi-Oliveria et al. [19] which validated the CTQ scale on Brazilian children, were stated that alternative models should be focused due to cultural differences. Finally, we did not evaluate the participants whether they have any significant psychopathology which might complicate the results.

\section{Conclusion}

Contrary to the results in the literature, we did not find a directly proportional relationship between adverse childhood experiences and smoking addiction. This important finding suggests that further studies should be done on whether ACE may lead not only to cigarette addiction but also to other serious conditions such as substance abuse, mental and physical health problems. Determinants of child maltreatment are multi-systemic, it therefore, makes sense that in counties with different social, cultural, and economic conditions, the consequences of child maltreatment will also be different.

\section{Conflict of interest: None.}

Funding: This study was not supported by any organization or entity. The authors have no financial involvement with any organization or entity. No writing assistance was utilized in the production of this manuscript.

Ethical permissions: The study was conducted in compliance with the ethical principles according to the Declaration of Helsinki. The legal and ethical approval of the study was obtained from the Hospital Clinical Research Ethics Committee, Institutional Review Board No. 26/16. 


\section{References}

1. World Health Organization. WHO REPORT ON THE GLOBAL TOBACCO EPIDEMIC, 2019 Offer help to quit tobacco use. World Health Organization, Geneva 2019: 110

2. Özer N, Kılıçkap M, Tokgözoğlu L, et al. Data on smoking in Turkey: Systematic review, meta-analysis and meta-regression of epidemiological studies on cardiovascular risk factors. Turk Kardiyol Dern Ars. 2018; 46(7): 602-612, doi: 10.5543/tkda.2018.85349, indexed in Pubmed: 30391989.

3. Acar S, Kaylı DS, Yararbaş G. A comparison of smokers, non-smokers, and those undergoing treatment in terms of attitudes on coping with stress and psychological resilience. Addicta: The Turkish Journal on Addictions. Addicta: The Turkish J on Add. 2019; 6(3): 539-566, doi: 10.15805/addicta.2019.6.3.0029.

4. Mehta D, Kelly AB, Laurens KR, et al. Child Maltreatment and Long-Term Physical and Mental Health Outcomes: An Exploration of Biopsychosocial Determinants and Implications for Prevention. Child Psychiatry Hum Dev. 2021 [Epub ahead of print], doi: 10.1007/s10578021-01258-8, indexed in Pubmed: 34586552.

5. Dovran A, Winje D, Overland SN, et al. Psychometric properties of the Norwegian version of the Childhood Trauma Questionnaire in high-risk groups. Scand J Psychol. 2013; 54(4): 286-291, doi: 10.1111/sjop.12052, indexed in Pubmed: 23672336.

6. Saunders BE, Adams ZW. Epidemiology of traumatic experiences in childhood. Child Adolesc Psychiatr Clin N Am. 2014; 23(2): 167-84, vii, doi: 10.1016/j.chc.2013.12.003, indexed in Pubmed: 24656575.

7. Fagerstrom KO, Heatherton TF, Kozlowski LT. Nicotine addiction and its assessment. Ear Nose Throat J. 1990; 69(11): 763-765, indexed in Pubmed: 2276350.

8. Bernstein D, Stein J, Newcomb M, et al. Development and validation of a brief screening version of the Childhood Trauma Questionnaire. Child Abuse Negl. 2003; 27(2): 169-190, doi: 10.1016/s01452134(02)00541-0, indexed in Pubmed: 12615092.

9. Giovino G, Mirza S, Samet J, et al. Tobacco use in 3 billion individuals from 16 countries: an analysis of nationally representative cross-sectional household surveys. The Lancet. 2012; 380(9842): 668-679, doi: 10.1016/s0140-6736(12)61085-x, indexed in Pubmed: 22901888.
10. Vest BM, Hoopsick RA, Homish DL, et al. Childhood trauma, combat trauma, and substance use in National Guard and reserve soldiers. Subst Abus. 2018; 39(4): 452-460, doi: 10.1080/08897077.2018.1443315, indexed in Pubmed: 29485365.

11. Meadows AL, Strickland JC, Kerr MS, et al. Adverse Childhood Experiences, Tobacco Use, and Obesity: A Crowdsourcing Study. Subst Use Misuse. 2019; 54(10): 1743-1749, doi: 10.1080/10826084.2019.1608254, indexed in Pubmed: 31037991.

12. Martínez-Ortega JM, Jurado D, Gurpegui M. Nicotine dependence vs. daily smoking as a meaningful variable: implications for clinical and epidemiological psychiatric studies. Prog Neuropsychopharmacol Biol Psychiatry. 2008; 32(8): 1972 1977, doi: 10.1016/j.pnpbp.2008.09.015, indexed in Pubmed: 18854205

13. Oncel SY, Dick DM, Maes HH, et al. Risk factors influencing smoking behavior: a Turkish twin study. Twin Res Hum Genet. 2014; 17(6): 563-573, doi: 10.1017/thg.2014.43, indexed in Pubmed: 25431287.

14. Collado A, Felton JW, Taylor H, et al. Conscientiousness explains the link between childhood neglect and cigarette smoking in adults from a low-income, urban area-the differential effects of sex. Child Abuse Negl. 2019; 88: 152-158, doi: 10.1016/j.chiabu.2018.10.015, indexed in Pubmed: 30508683

15. Roberts ME, Fuemmeler BF, McClernon FJ, et al. Association between trauma exposure and smoking in a population-based sample of young adults. J Adolesc Health. 2008; 42(3): 266-274, doi: 10.1016/j. jadohealth.2007.08.029, indexed in Pubmed: 18295135.

16. Nichols HB, Harlow BL. Childhood abuse and risk of smoking onset. J Epidemiol Community Health. 2004; 58(5): 402-406, doi: 10.1136/jech.2003.008870, indexed in Pubmed: 15082739.

17. Bonomi AE, Anderson ML, Nemeth J, et al. History of dating violence and the association with late adolescent health. BMC Public Health. 2013; 13: 821, doi: 10.1186/1471-2458-13-821, indexed in Pubmed: 24015863

18. Al Mamun A, Alati $R$, O'Callaghan $M$ et al Does childhood sexual abuse have an effect on young adults' nicotine disorder (dependence or withdrawal)? Evidence from a birth cohort study. Addiction. 2007; 102(4): 647-654 doi: 10.1111/j.1360-0443.2006.01732.x, indexed in Pubmed: 17286640

19. Grassi-Oliveira R, Cogo-Moreira H, Salum GA, et al. Childhood Trauma Questionnaire (CTQ) in Brazilian samples of different age groups: findings from confirmatory factor analysis. PLoS One. 2014; 9(1): e87118, doi: 10.1371/journal.pone.0087118, indexed in Pubmed: 24475237 